\title{
Electrohydraulic sheet metal forming with flexible tools
}

\author{
Holger Pegel ${ }^{1,3^{*}}$, Lasse Langstädtler ${ }^{1,3}$, Marius Herrmann ${ }^{1,3}$, Christian Schenck $^{1,2,3}$, and Bernd Kuhfuss ${ }^{1,2,3}$ \\ ${ }^{1}$ bime, Bremen Institute for Mechanical Engineering, Badgasteiner Str. 1, 28359 Bremen \\ ${ }^{2}$ MAPEX Center for Materials and Processing \\ ${ }^{3}$ University of Bremen
}

\begin{abstract}
In cold metal forming usually a die and a punch are required to form sheet metal in the desired shape. These two parts of the tool need to be produced of hardened materials in high precision. In this paper it is shown, that by using electrohydraulic forming the punch is replaced by a hydraulic punch and the die can be made easily out of softer materials that seem absolutely not suited at first sight. This allows for rapid and cheap manufacturing of sheet metal parts.
\end{abstract}

Keywords: Metal Forming, Die, Rapid tooling

\section{Introduction}

Cold forming of sheet metals is a convenient and high efficient way for bulk production of a broad variety of parts. A conventional forming process is the mechanical deep drawing. In this process, a blank is formed using two corresponding tool parts. These tools directly reproduce their geometry and surface into the parts. Hence, both die parts must provide a sufficient quality concerning these features as well as a high durability to endure high process loads during forming. In consequence, the production of those tools themselves are cost and time intensive, since they are usually made of hard working steel and require narrow tolerances. To reduce the costs and the manufacturing time one tool side is replaced by a shapeless and contactless working shock wave like it is provided by the electrohydraulic forming (EHF) process. Doing so also the costly tolerances between the die parts become obsolete.

Electrohydraulic forming is a high speed forming process first researched by Yutkin in 1955 [1]. The forming energy is produced by shorting an electric circuit. When the circuit is shorted an electric arc is discharged or an aluminum wire is vaporized within a liquid resulting in a shock wave. The effect of the electric wire explosion is known since 1774 [2]. The shock wave is unlike the most shock waves not spherical but cylindrical. This is a result of the initiation of the shock wave that is not located in a single point but along the whole wire or along the travel of the electric arc with a velocity of up to $3.5 \mathrm{~km} / \mathrm{s}[1,3-$ $6]$. In this process the shock wave within the fluid replaces a mechanic punch. Due to this only a one sided die is needed. At conventional hydraulic and electrohydraulic forming the die is produced from metal with money and time consuming methods like hard milling. This is only profitable for mass production of the formed parts by this tools. In recent times, customizability and smaller production series as well as rapid production become more and more important. Since in electrohydraulic forming the force in not applied quasi static but with a very short impulse the die material needs to fulfill the requirement of a high resistivity against short-time and high frequency excitation and not necessarily of high rigidity against static loads. Hence, the paradigm of designing dies can change with the changing requirements. These thoughts inspired an experimental study in which different materials were tested concerning their ability to be applied for fast and cheap die manufacturing.

\section{Experimental setup}

For all experiments a modular forming setup was used which is illustrated in Figure 1. The modular design of the setup allowed changing of all components to test a diversity of different parameters and die geometries. The capacitor bank with a capacity of $104 \mu \mathrm{F}$ and a maximal loading voltage of $2500 \mathrm{~V}$ was connected to one connector on each side of the setup. The connectors were equipped with a spring mechanism to hold the wire in place. The wire featured a diameter of $\mathrm{d}_{\mathrm{w}}=0.3 \mathrm{~mm}$ and was made out of $99.5 \%$ aluminum (aluminum alloy 1050). The connectors were insulated from the steel pressure chamber with PLA (polylactic acid) plastic bushings. The chamber was basically a cavity in a steel cylinder. On top of the chamber was an opening which

\footnotetext{
* Corresponding author: pegel@bime.de
} 
could be sealed and opened with a screw for filling up the chamber with distilled water.

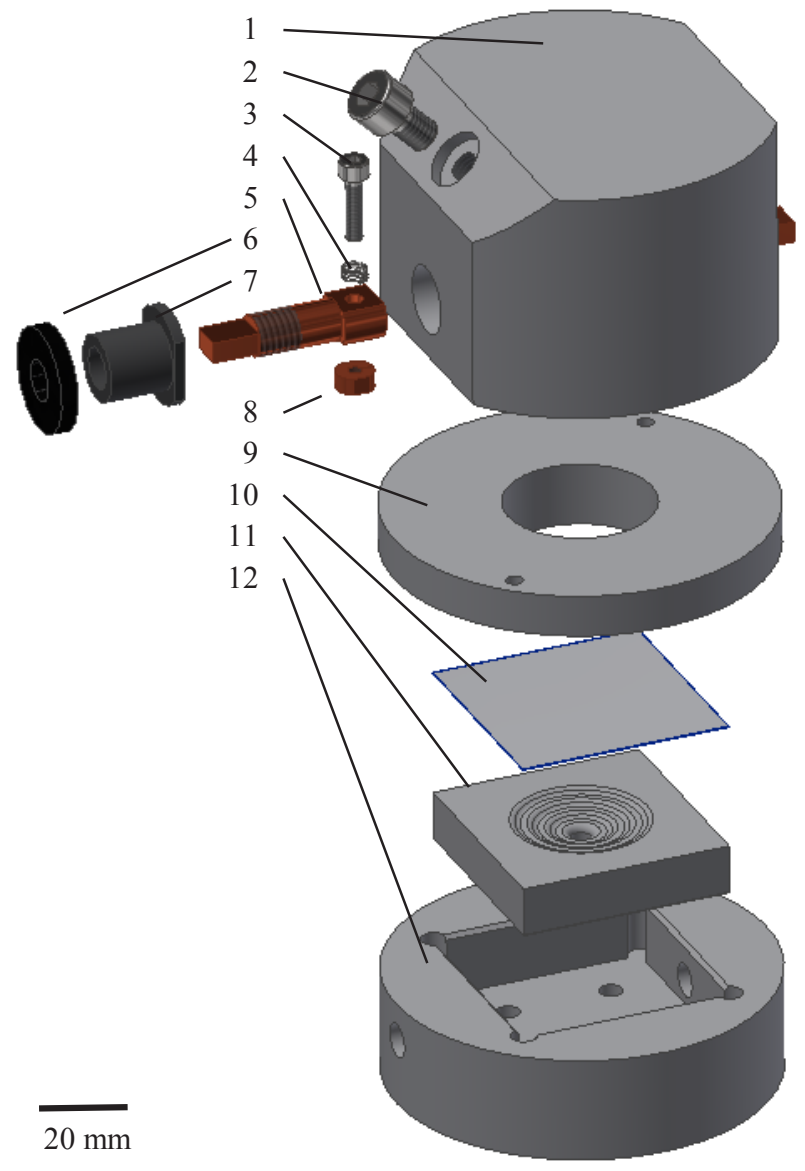

Fig. 1 Experimental setup: 1 pressure chamber; 2 closing screw; 3,4,8 wire clamp; 5 connector; 6,7 insulation; 9 aperture; 10 sample; 11 die; 12 base plate.

Underneath the chamber was an aperture made of A17075 restricting the shock wave and as a result the forming area to a $34 \mathrm{~mm}$ circle. The sample was directly located under the aperture. The sample was a square piece of sheet aluminum with a side length of $\mathrm{L}=50 \mathrm{~mm}$ and a thickness of $\mathrm{s}_{0}=0.5 \mathrm{~mm}$. Under the sheet metal was the forming die. The die was fixed in a base plate. This base plate distributed the closing forces of $\mathrm{F}_{\mathrm{cl}}=50 \mathrm{kN}$ that were provided by a hydraulic press across the die.

The dies were basically shaped as a prismatic square $\left(50 \times 50 \times 12 \mathrm{~mm}^{3}\right)$ with a circular forming geometry in the center. The forming geometry which is displayed in Figure 2 was a triple-staged bore with a stage size of $1 \mathrm{~mm}$ each and a transition radius of $1.7 \mathrm{~mm}$. Located in the center is a $5.1 \mathrm{~mm}$ bore to handle with the compressed air during the process which is important to receive a good result [7]. The cavity in stages was chosen to enable a fast and easy evaluation of the forming results.

For some tested materials a 3D printed frame structure was applied which is shown in Figure 3. This die holder provided a cylindrical cavity that could be filled with liquid or pasty materials to be shaped off with finished inlets. The plug is necessary to be able to remove the inlets from the forming frame easily.
Dies made from five different materials were tested which were produced in three different ways. PLA (polylactide) was 3D printed with an infill of $90 \%$, silicone and gypsum were casted in molds and sand and modeling clay were embossed with a 3D printed forming stamp into the right couture. The die made out of PLA is shown in Figure 2 and the other four are shown in Figure 4. All dies were tested with loading voltages of $1000,1500,2000$ and $2500 \mathrm{~V}$.

a)

b)

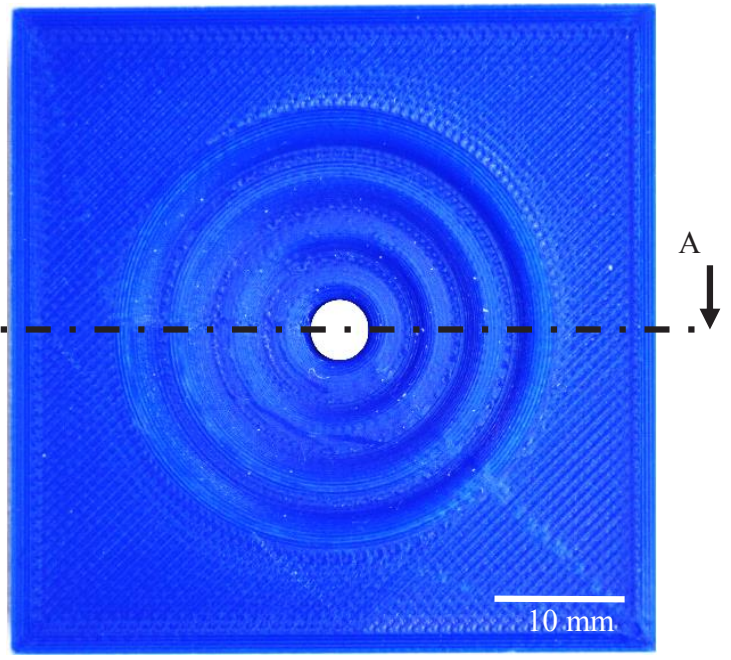

A-A

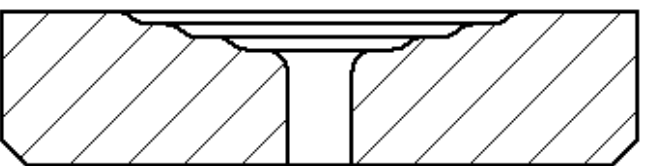

Fig. 2 Die geometry: a) top view on PLA die (photography), b) cross section.

a)

b)
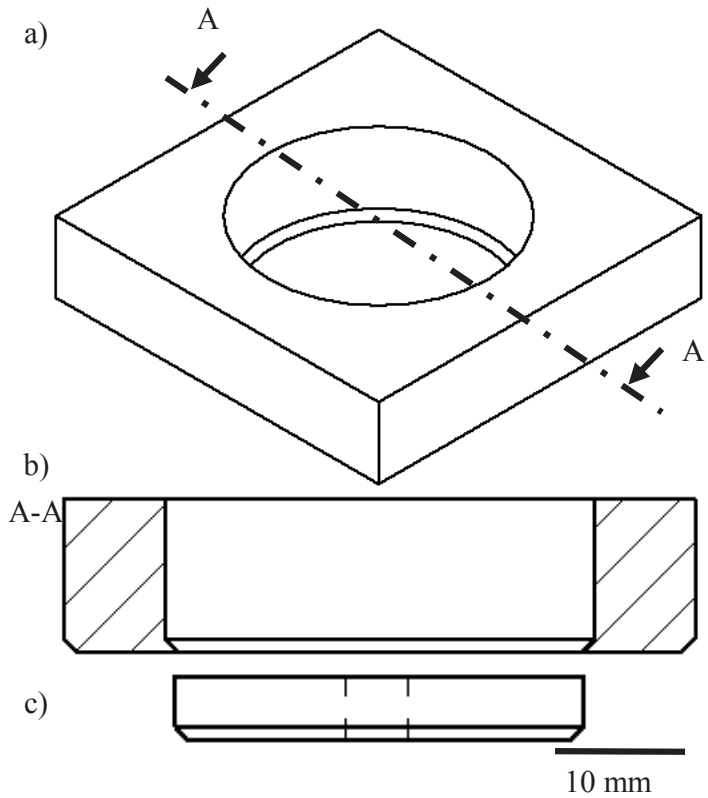

Fig. 3 Sketch: a) the forming frame, b) cross section and c) the plug. 

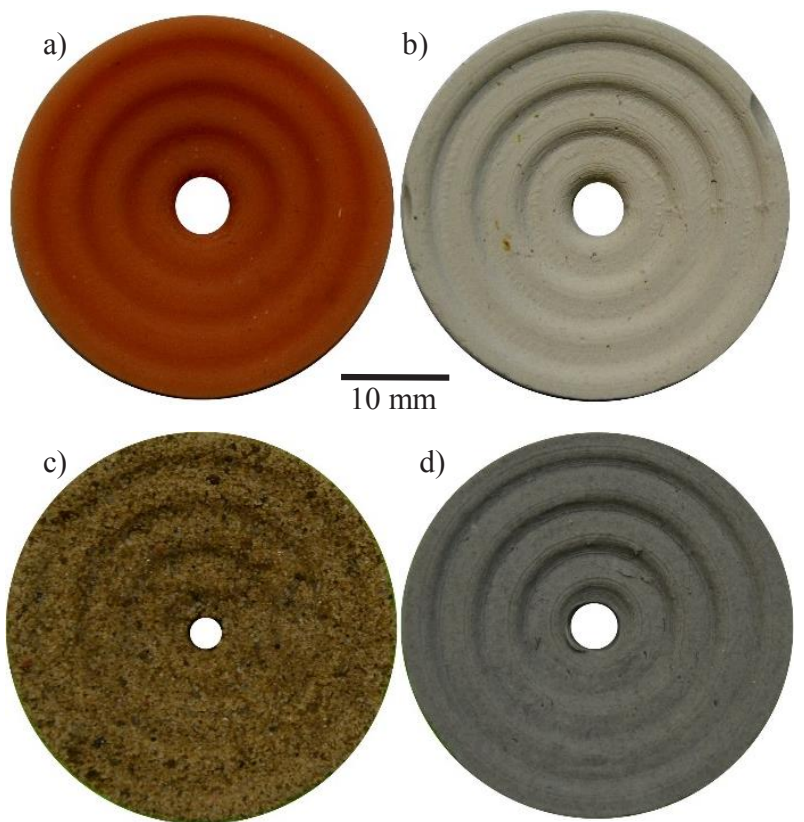

Fig. 4 Dies: a) silicone (casted), b) gypsum (casted), c) sand (embossed), d) modeling clay (embossed).

\section{Execution and observation}

\subsection{Tool Handling}

During the conduction of the experiments it became obvious that some of the die materials were easier to handle than others especially taking into consideration the involvement of water in the process. The handling of the 3D printed die was the easiest. It was reusable, ready as soon as it was printed and it was waterproof. The gypsum and silicone dies were also easy to handle. After filling the casting molds, they just had to cure before they were ready to use. The gypsum die was single-use whereas the silicone die was reusable. Modeling clay proved to be easy to shape and easy to reshape for reuse. The most complicated handling was observed with the sand die. The shape turned out to be very fragile and the surface structure varied with every new die embossing. Additionally, the used kind of sand became instable and not shapeable when it became wet.

\subsection{Measurement procedure}

All samples had been scanned with a 3D scanner from the side that was touching the die during the process, which is the top side in Figure 5 a). The measurements were made with a confocal microscope, see Figure $5 \mathrm{~b}$ ) which has the same perspective like Figure 5 a). As this research was conducted to explore the feasibility, every experiment was repeated only three times and only one sample was measured exemplarily for each set of parameters.

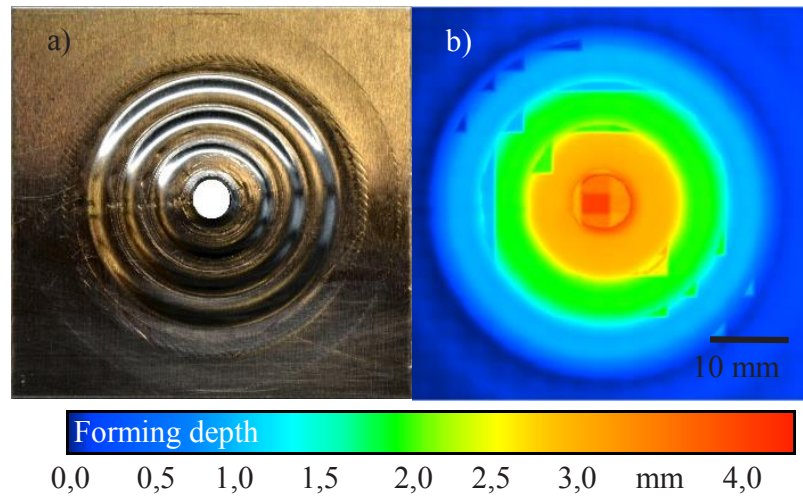

Fig. 5 Sample formed with $1500 \mathrm{~V}$ in a 3D printed PLA die: a) Picture, b) 3D scan.

\section{Result and discussion}

Best results were achieved with the 3D printed dies, Figure 5 a). All stages of the die were properly formed and the circularity was quite well. The PLA die surpassed expectations. Besides the form also the surface was imprinted. The structure of the printed die is clearly visible in the sample (compare Figure 2 a) and Figure 5 a)). In Figure 6 the height profiles of the samples are displayed. These are deducted from the 3D scans. Further, the PLA die was capable to be applied as a cutting tool. The center bore of the die worked as a cutting edge despite the smooth transition radius. During the conducted experiments no tear or wear was visible at the PLA die after the twelve conducted experiments.

With an increase of the loading voltage the shock wave got stronger and quicker as a result the forming force increased which usually results in a more detailed forming result [8]. In case of the PLA dies the forming result stayed more or less the same except for the test with $1000 \mathrm{~V}$. In this test the sheet metal was not cut in the center due to the lower forming energy.

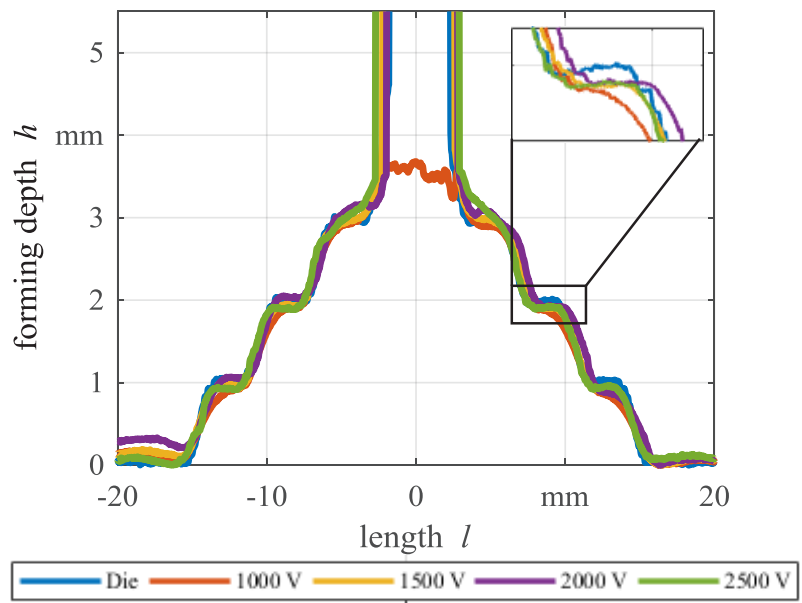

Fig. 6 Height profile of the ideal die and the sheets formed in the PLA die with different loading voltages.

The 2D height profiles of the samples made with gypsum dies show that the individual stages of the die were smoothened and not very defined see Figure 7. Also the contour is always above the designed die outline. This means that the die was compressed during the process. 
Most likely this is a result of the porose structure of gypsum. Due to deformation of the die for every test a new die was used. By the higher average forming depth with the same base diameter, the whole sample appeared pointier and the steps were formed only rudimentarily. Similar to the PLA die cutting with the gypsum die was possible at $\mathrm{U} \geq 1500 \mathrm{~V}$.

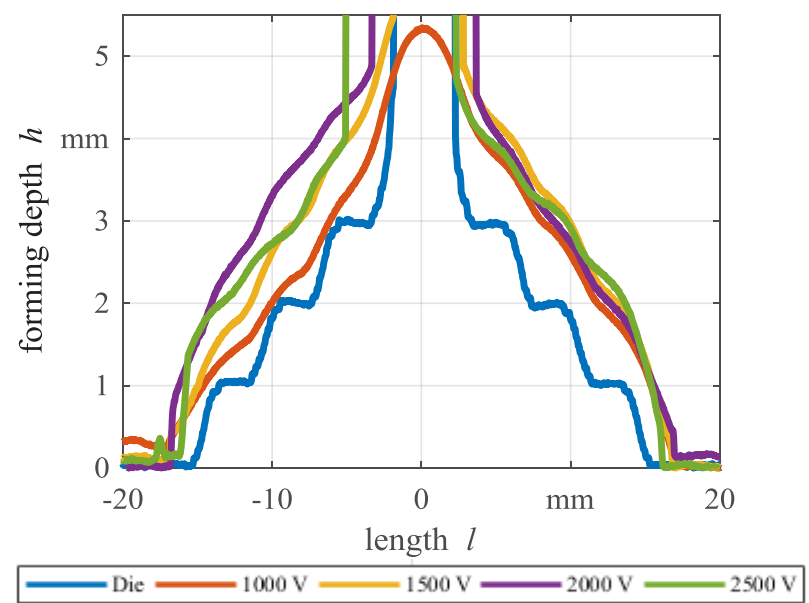

Fig. 7 Height profile of the ideal die and the sheets formed in the gypsum die with different loading voltages.

The samples made with a die out of modeling clay showed a very different result. The shape of the die was reduced to a cone like shape with concave sides and the stages were not recognizable, see Figure 8. Unlike the previous results none of the samples were cut in the center. This shows that with the modeling clay die the very rough shape of the cone could be formed but no precise stages. The die was deformed during every experiment and the center hole closed, but the die could easily be reshaped with the forming stamp and then used again. The sample made with $2500 \mathrm{~V}$ showed a hutch in the center against the forming direction. This may be a result of trapped and compressed air between the die and the sample due to the closing of the center bore. Summarized, the tested modeling clay is not a suitable die material for detailed tool geometries.

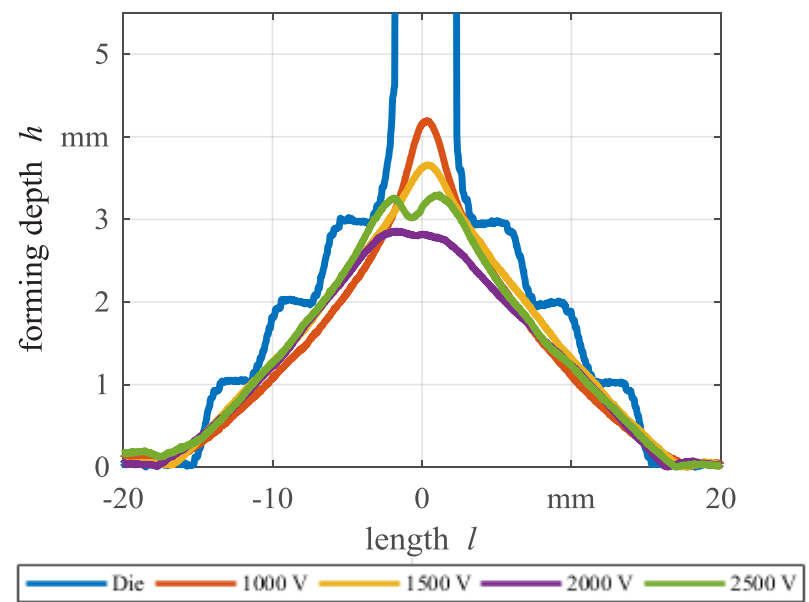

Fig. 8 Height profile of the ideal die and the sheets formed in the modeling clay die with different loading voltages.
The dies made out of sand produced a forming result worse than the one made with the modeling clay die. The stages are again not visible instead a cone like shape was reached with a major stage at a forming depth of about $1 \mathrm{~mm}$, see Figure 9. This over all stages outside perimeter seems to be restricted by the forming frame and not the die itself. Only the test with $2000 \mathrm{~V}$ loading voltage has a smoother stage at an even higher forming depth. It seems like the whole sand die was compressed down about $1 \mathrm{~mm}$ and then a small, pointy cone formed in the center. Cutting with sand dies is also possible at $\mathrm{U} \geq 2000 \mathrm{~V}$. The surface of the sample is very rough due to the structure of the sand that was transferred onto the sheet metal. The die looked completely destroyed after every experiment and needed to be remodeled. In combination with the difficulties in the die handling, sand or at least this kind of sand does not seem to be suitable as a die material for electrohydraulic forming without further preparation like preconsolidation or the use of binder.

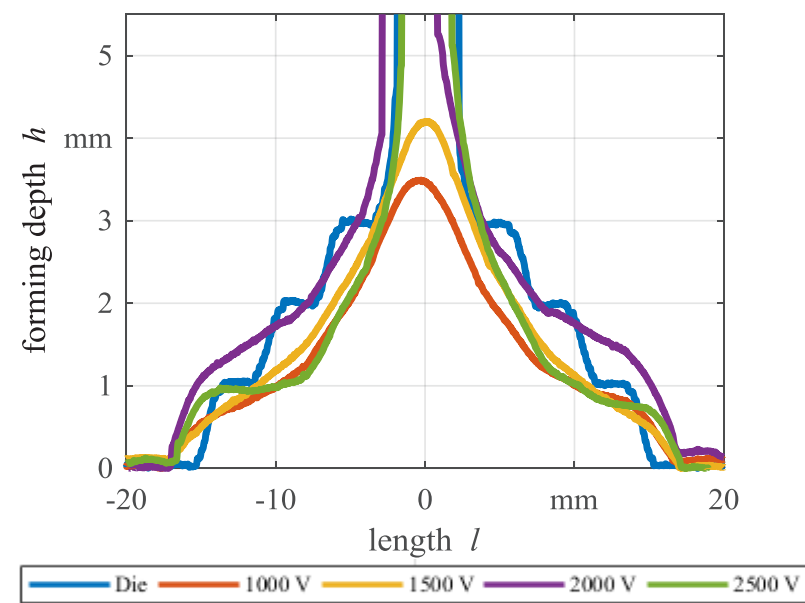

Fig. 9 Height profile of the ideal die and the sheets formed in the sand die with different loading voltages.

The fifth tested die material was silicone. Figure 10 shows that the shape of the samples was also smoothened and the stages were not recognizable. Tree of the samples showed a very pointy tip in the center. When the sample was made with $U \geq 2000$, the silicone die had a darker color in the center and the smell of burned plastic was noticeable. Besides that, no wear and tear was detected

For a better comparison the contour accuracy was evaluated by defining the quality measure RIQ (relative integral quotient) by equation (1). The formed cross section was related to the cross section of the ideal die. The values in the interval $l \in[-5,5]$ were neglected to consider the partial cuttings in the center. 


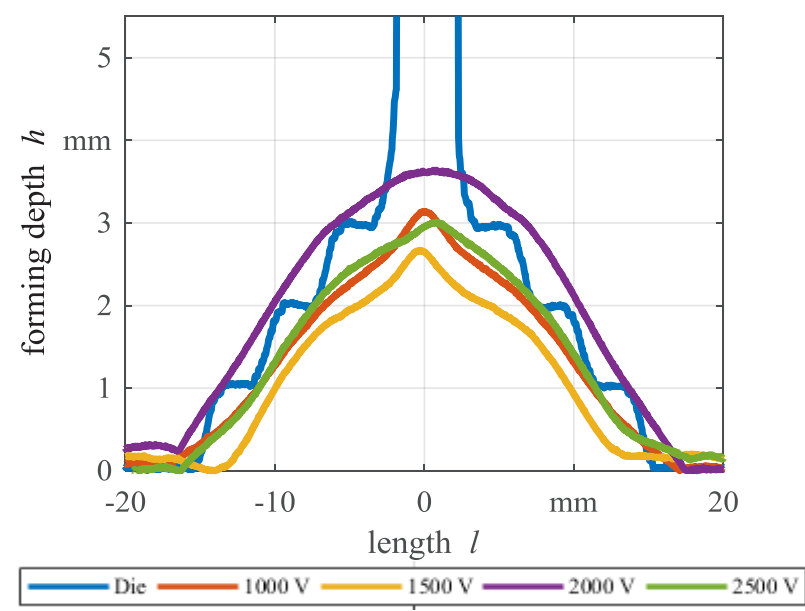

Fig. 10 Height profile of the ideal die and the sheets formed in the silicone die with different loading voltages.

$$
R I Q=\frac{\int_{15}^{-5} h_{\text {sample }} d l+\int_{5}^{15} h_{\text {sample }} d l}{\int_{-15}^{-5} h_{\text {die }} d l+\int_{5}^{15} h_{\text {die }} d l} * 100 \%
$$

The relative integral quotients in Figure 11 show for the samples made with the PLA die a nearly perfect RIQ between $95 \%$ and $102 \%$. Interestingly the highest RIQ was achieved with $2000 \mathrm{~V}$ and not with the highest loading voltage.

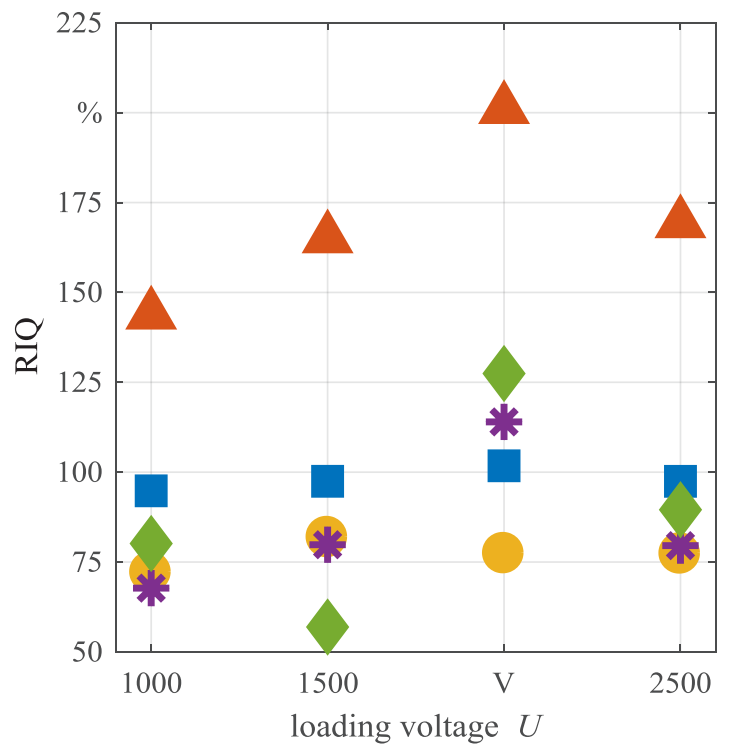

PLA $\triangle$ Gypsum $\bigcirc$ modeling clay * Sand $>$ Silicone

Fig. 11 RIQ for different loading voltage and different dies.

The RIQ of the samples made with a gypsum die are always considerably above $100 \%$ with values between $144 \%$ and $201 \%$. The RIQ rises with an increase in loading voltage up to $2000 \mathrm{~V}$ and then drops back down at $2500 \mathrm{~V}$. When modeling clay was used as a die material the RIQ is very stable with values between $72 \%$ and $82 \%$. Especially the values for $1000 \mathrm{~V}, 1500 \mathrm{~V}$ and $2500 \mathrm{~V}$ vary only about $4 \%$. The samples made with a sand die show a larger variation with the RIQs between
$68 \%$ and $114 \%$ with the highest value at $U=2000 \mathrm{~V}$. If silicone is used as material for the die the RIQs are the most inconsistent of all tested die materials. With a variation between $57 \%$ and $127 \%$ and no recognizable trend.

It is an unexpected result, that except for modeling clay which produced a very stable RIQ all other die materials reached the highest RIQ at $\mathrm{U}=2000 \mathrm{~V}$ and not at the highest loading voltage. It is assumed that, with $\mathrm{U}=2500 \mathrm{~V}$ the sample reached a very high speed when it hit the die and bounced back of the die.

\section{Excursion}

To illustrate a farfetched possibility of the new approach of flexible tools a jelly bear was attempted to be used as a forming tool. Instead of a die a jelly bear was directly placed in the die holder. The attempt was realized with $1500 \mathrm{~V}$ and with an aluminum sheet with $\mathrm{s}_{0}=200 \mu \mathrm{m}$ instead of the previously used $500 \mu \mathrm{m}$. The result is a nearly perfect copy of the jelly bear shown in Figure 12). Even the small details like the eyes and the dents in the jelly bears belly are visible. This shows that even with very flexible die materials a good forming result can be achieved and using very thin sheet metal the level of details can be increased. a)

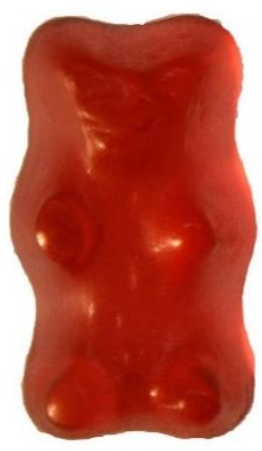

b)

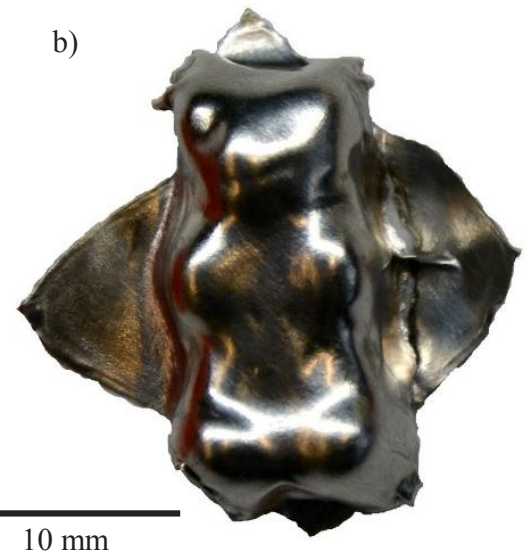

Fig. 12 Molding of a jelly bear: a) tool (common candy); b) shaped sheet metal $\left(\mathrm{s}_{0}=200 \mu \mathrm{m}\right)$.

\section{Conclusion and outlooks}

To discover the possibility of forming sheet metal in dies made out of a variety of much softer materials compared to hardened steel experiments were executed. The chosen forming technique was a high speed forming process, the electrohydraulic forming. Five chosen materials PLA plastic, gypsum, modeling clay, sand, and silicone provided different flexibilities and structures. Dies from all materials were tested with a circular staged shape with variation of loading voltages that resulted in different forming energies in the process. The main results of the conducted experiments are:

- Electrohydraulic forming with the presented die materials is generally possible.

- $\quad 3 \mathrm{D}$ printed PLA dies provided the best forming results. 
- Even cutting was possible with PLA, gypsum and sand dies.

- Elastic flexibility and even plastic deformation of the die are not criterions of exclusion but must be considered in the design process of the die.

- Softer die materials provide usable results if no small details or sharp transitions are desired.

- With new die materials, rapid sheet metal forming operations are possible when electrohydraulic forming is applied.

In further experiments more complex die geometries should be investigated, as well as different sample sizes. Also other high speed forming processes like electromagnetic forming should be considered for sheet metal forming with flexible tools. In addition, other operations like cutting with those tools need to be investigated. In the design process, the dynamic behavior of the dies in the range of high frequency excitation must be taken into account to find optimized solutions.

\section{References}

1. K. Siegert, Blechumformung Verfahren, Werkzeuge und Maschinen, (2015)

2. Y.A. Kotov,. Nanotechnologies in Russia. 4, Nos. 7 8, (2009).

3. M. Woetzel, M.J. Löffler, E.Spahn, H. Ritter Preliminary examination of high-velocity metalshaping with electrical wire explosion (2006)

4. G.S. Sarkisov, S.E. Rosenthal, K.R. Cochrane, K.W. Struve, C. Deeney, D.H. McDaniel PHYSICAL REVIEW. 71, (2005)

5. Y.E. Krasik, A. Grinenko, A. Sayapin, S. Efimov, A. Fodotov, V. Gurovich, I. Oreshkin, IEEE Transactions on plasma Science Vol.36 No.2 (2008)

6. W. Müller, Zeitschrift für Physik, Bd. 149, p. 397411. (1957)

7. W. Homberg, C. Beerwald, A. Pröbsting, 4th International Conference of High Speed Forming. (2010)

8. A. Abdelkefi, P. Malécot, N. Boudeau, N. Guermazi, N., The International Journal of Advanced Manufacturing Technology. (2016) 